Chronic Obstructive Pulmonary Diseases: Journal of the COPD Foundation

\title{
Azithromycin and COPD Exacerbations in the Presence or Absence of Symptoms or Active Treatment for Gastroesophageal Reflux
}

Frederick L. Ramos, MD, ${ }^{1}$ Sarah M. Lindberg, MPH, ${ }^{2}$ Jason S. Krahnke, DO, ${ }^{1}$ John Connett, PhD, ${ }^{2}$ Richard K. Albert, MD, ${ }^{3}$ and Gerard J. Criner, MD, ${ }^{1}$ for the COPD Clinical Research Network

\begin{abstract}
Introduction: Gastroesophageal reflux disease (GERD) is common in chronic obstructive pulmonary disease (COPD) and is associated with COPD exacerbations. Since macrolides have prokinetic effects and consequently may decrease GERD, we hypothesized that azithromycin may decrease exacerbations by decreasing GERD.

Methods: We conducted a retrospective review of data collected in a prospective, randomized, controlled trial of azithromycin for preventing COPD exacerbations. Participants were classified as having GERD on the basis of having a history of GERD or having a history or being treated for GERD.

Results: We analyzed 1116 participants, 478 (43\%) and 568 (51\%) had GERD on the basis of history and history or treatment respectively. Individuals with GERD developed exacerbations sooner and more frequently, and were more likely to be hospitalized than those without GERD but the difference only reached significance when GERD was defined by history or treatment $(P=0.02,0.02$, and 0.03, respectively). Azithromycin reduced exacerbations regardless of the presence of GERD, but had a greater effect in those without GERD.

Conclusions: GERD is associated with more frequent and severe COPD exacerbations. Azithromycin reduces COPD exacerbations regardless of the presence or absence of GERD but does so to a greater degree in individuals without GERD.
\end{abstract}

Abbreviations: gastroesophageal reflux disease, GERD; acute exacerbations of COPD, AECOPD; forced expiratory volume in 1 second, $\mathbf{F E V}_{\mathbf{1}}$; forced vital capacity, FVC; proton pump inhibitors, PPI; inhaled corticosteroids, ICS; long-acting muscarinic agonist, LAMA; longacting beta agonist, LABA.

Funding Support: The National Heart, Lung, and Blood Institute (ClinicalTrials.gov number: NCT00325897) provided funding for this study.

Date of Acceptance: July 9, 2014

Citation: Ramos FL, Lindberg SM, Krahnke JS, et al. Azithromycin and COPD exacerbations in the presence or absence of symptoms or active treatment for gastroesophageal reflux. J COPD F. 2014; 221-228. doi: http://dx.doi.org/10.15326/jcopdf.1.2.2014.0132

\section{This study was presented at the American Thoracic Society International Conference, Philadelphia, PA, May 17 to 22, 2013.}

1 Section of Pulmonary and Critical Care Medicine, Temple University School of Medicine, Philadelphia, PA

2 Division of Biostatistics, University of Minnesota, Minneapolis

3 Denver Health, Denver, CO and University of Colorado-Denver, Aurora, CO

\section{Address correspondence to:}

Frederick L. Ramos, MD,

785 Parkinson Pavilion, 3401 North Broad Street, Philadelphia, PA 19140; phone: (215)707-2526;

Frederick.ramos@tuhs.temple.edu

\section{Keywords:}

gastroesophageal reflux disease; chronic obstructive pulmonary disease; chronic obstructive pulmonary disease exacerbations; azithromycin 


\section{Introduction}

The prevalence of gastroesophageal reflux disease (GERD) in COPD ranges from $19 \%$ to $54 \%$ when diagnosed by symptoms, and from $57 \%$ to $62 \%$ when diagnosed by 24-hour $\mathrm{pH}$ probe testing. ${ }^{1-6}$ In normal individuals, the prevalence of GERD ranges from $<5 \%$ to $20 \%{ }^{7}$ Acid aspiration into the airway or esophagus causes bronchoconstriction ${ }^{8,9}$ and both retrospective and prospective studies indicate that COPD patients with GERD have more acute exacerbations of COPD (AECOPDs) and worse outcomes than those without GERD. ${ }^{3,5,6,10}$ One small, single-blind prospective randomized trial in COPD individuals who had symptoms of GERD found that proton pump inhibitors decreased the frequency of AECOPDs. ${ }^{11}$

We recently reported that azithromycin reduced AECOPD in COPD individuals who were at increased risk of having an AECOPD and attributed the benefit to the macrolide's anti-microbial and/or antiinflammatory effects. ${ }^{12}$ However, azithromycin may potentially reduce exacerbations by decreasing GERD via its prokinetic effects and ability to decrease acid reflux. ${ }^{13,14}$ Accordingly, the purpose of this study was to determine if azithromycin had a more pronounced effect in preventing AECOPDs in COPD individuals with or without GERD.

\section{Methods}

\section{Study Participants}

We performed a retrospective review of data collected prospectively in a randomized, controlled trial of azithromycin (250 mg, taken orally, once daily or a placebo added to the usual care of COPD) that was conducted over a one-year period. ${ }^{12}$ All the participating institutions had approval by their respective institutional review boards. All participants provided written consent. Participants in the azithromycin study were at least 40 years old and had a diagnosis of COPD which was defined by a forced expiratory volume in 1 second $\left(F E V_{1}\right)$ to forced vital capacity (FVC) ratio of $<70 \%$ with an $\mathrm{FEV}_{1}<80 \%$ after bronchodilator use and at least a 10 pack-year smoking history. To enrich the population for individuals who were more likely to have AECOPDs, each participant had to either be using continuous supplemental oxygen or have received systemic glucocorticoids, visited an emergency department or been hospitalized for an AECOPD within the year prior to enrollment. Individuals were excluded if they had asthma, a resting heart rate $>100$ beats/ minute, a corrected QT interval >450 milliseconds, used medications known to prolong the corrected QT interval or be associated with torsade de pointes (with the exception of amiodarone) or if they had hearing impairment documented by audiometric testing. ${ }^{12}$

\section{Study Design}

GERD was defined by having a history of, or being treated for GERD. At the time of enrollment, participants were asked whether they had GERD or heartburn. Those responding yes to the question were considered to have GERD on the basis of history. A list of all medications was also recorded. Those taking proton pump inhibitors, histamine-2 receptor blockers and/or antacids were considered to have GERD on the basis of treatment. All other participants were considered to not have GERD. An exacerbation was defined as "a complex of respiratory symptoms (increased or new onset) of more than one of the following: cough, sputum, wheezing, dyspnea, or chest tightness lasting at least 3 days requiring treatment with antibiotics or systemic steroids." 12 The primary outcome was the time to first AECOPD. Secondary outcomes were the rates of AECOPDs, exacerbation-related office visits, emergency department visits, and hospitalizations.

\section{Analysis}

Categorical data were expressed as number and percentage. Continuous data were expressed as mean \pm standard deviation. Univariate analysis of categorical and continuous data utilized the chi-square and t-test, respectively. Proportions free of exacerbations were taken from a life-table estimate and $\mathrm{P}$ values were calculated from the PHREG procedure. Event rates were determined by dividing the number of events by the person to years of follow-up. All event rates were compared using a zero-inflated negative binomial model with age, gender, current smoking, randomization to either azithromycin or placebo group, long term oxygen therapy, $\mathrm{FEV}_{1}$, hospitalization in previous year, and body mass index added as covariates. Time to the first AECOPD is reported as median and $95 \%$ confidence intervals. $\mathrm{P}<0.05$ was considered significant.

\section{Results}

The azithromycin trial enrolled 1117 individuals. One 
of these was excluded because the question regarding GERD was not answered leaving 1116 individuals in the present analysis. When defined by history, GERD was present in 478 participants (43\%). When defined by history or treatment 568 participants had GERD (51\%) (Figure 1). The demographics of the participants and their clinical characteristics at the time of enrollment are summarized in Table 1 . Regardless of which GERD definition was used, participants with GERD were more commonly women, had a greater body mass index and had slightly greater $\mathrm{FEV}_{1}$ values (Table 1). Subsequent calculations of the various event rates included adjustments for the imbalances between groups in baseline variables.

Findings regarding the effect of GERD and/or azithromycin on AECOPDs were generally the same regardless of the GERD definition used. When defined by history, GERD participants tended to have a shorter

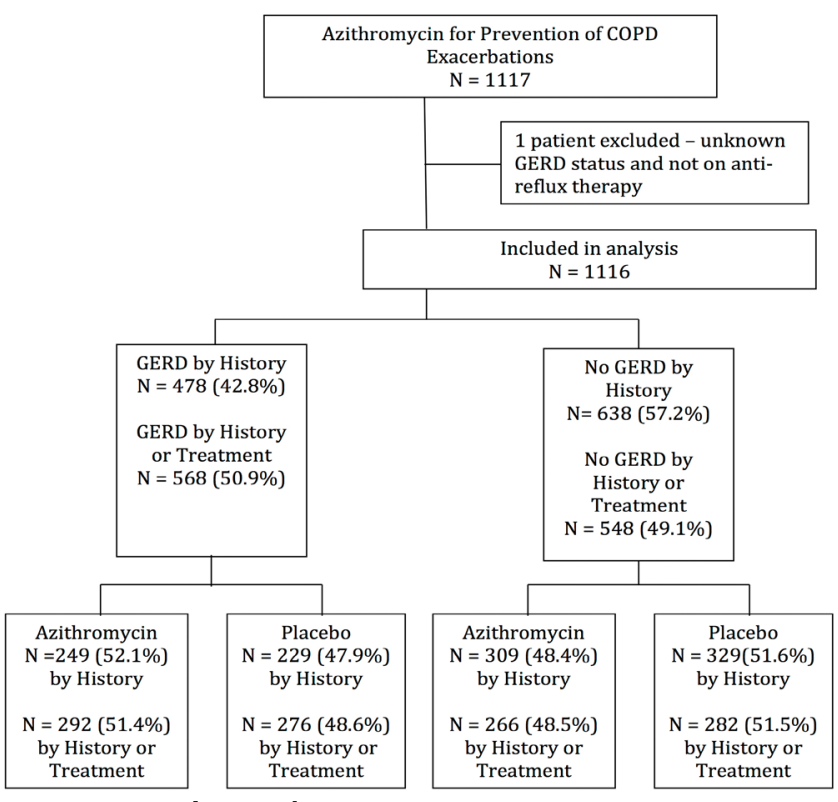

Figure 1. Study Population. time to the first AECOPD and a higher rate of AECOPDs than participants without GERD, but the differences did not reach statistical significance $(\mathrm{P}=0.09$ and 0.07 , respectively; Figure $2 \mathrm{~A}$ and Table 2A ). When defined by history or treatment, however, individuals with GERD had a shorter time to the first AECOPD and a higher rate of $\mathrm{AECOPD}$ (both $\mathrm{P}=0.02$; Figure $2 \mathrm{~B}$ and Table 2B). Compared with individuals taking a placebo, those receiving azithromycin had longer time to the first AECOPD and lower rate of AECOPDs regardless of the presence or absence of GERD (Tables 2A and 2B; Figure 3A and $3 B$ ).

We found no differences in the frequency of office visits or home management or emergency department visits in individuals with or without GERD regardless of how GERD was defined (Table 3A and $3 B$ ). However, individuals with GERD defined by history or treatment had a slightly but
Table 1. Demographic and Clinical Characteristics at Enrollment

\begin{tabular}{|c|c|c|c|c|c|c|}
\hline & \multicolumn{3}{|c|}{ Defined by History } & \multicolumn{3}{|c|}{ Defined by History or Treatment } \\
\hline & $\begin{array}{c}\text { GERD } \\
(\mathrm{N}=478)\end{array}$ & $\begin{array}{l}\text { No GERD } \\
(N=638)\end{array}$ & $P$ value & $\begin{array}{c}\text { GERD } \\
(\mathrm{N}=568)\end{array}$ & $\begin{array}{l}\text { No GERD } \\
(\mathrm{N}=548)\end{array}$ & $P$ value \\
\hline Age, years $($ mean $\pm S D)$ & $65 \pm 9$ & $65 \pm 9$ & 0.93 & $65 \pm 9$ & $65 \pm 9$ & 0.41 \\
\hline $\begin{array}{l}\text { Male, N (\%) } \\
\text { Race, N (\%) }\end{array}$ & $265(55)$ & $396(62)$ & 0.03 & $316(56 \%)$ & $345(63 \%)$ & 0.01 \\
\hline White & $387(81)$ & $517(81)$ & \multirow{3}{*}{0.14} & $462(81 \%)$ & $443(81 \%)$ & \multirow{3}{*}{0.11} \\
\hline Black & $63(13)$ & $98(15)$ & & $74(13 \%)$ & $87(16 \%)$ & \\
\hline Other & $28(6)$ & $23(4)$ & & $32(6 \%)$ & $19(4 \%)$ & \\
\hline Smoking history, pack-year $($ mean $\pm S D)$ & $58 \pm 32$ & $58 \pm 32$ & 0.30 & $58 \pm 33$ & $59 \pm 31$ & 0.85 \\
\hline Current smoker, $\mathbf{N}(\%)$ & $105(22)$ & $141(22)$ & 0.95 & $116(20 \%)$ & $130(24 \%)$ & 0.19 \\
\hline Alcohol use, drinks/wk (mean $\pm S D$ ) & $3 \pm 7$ & $3 \pm 7$ & 0.30 & $3 \pm 8$ & $3 \pm 7$ & 0.96 \\
\hline Corticosteroids and/or antibiotics in last $12 \mathrm{mo}, \mathrm{N}(\%)$ & $412(86)$ & $531(83)$ & 0.18 & $491(86 \%)$ & $453(83 \%)$ & 0.08 \\
\hline Chronic $\mathrm{O}_{2}$ use, $\mathrm{N}(\%)$ & $293(61)$ & $368(58)$ & 0.22 & $347(61 \%)$ & $315(57 \%)$ & 0.22 \\
\hline Body mass index, $\mathrm{kg} / \mathrm{m}^{2}($ mean $\pm \mathrm{SD})$ & $28 \pm 6$ & $27 \pm 6$ & 0.03 & $28 \pm 6$ & $27 \pm 6$ & 0.03 \\
\hline $\mathrm{FEV}_{1}(\%$ predicted $)($ mean $\pm \mathrm{SD})$ & $42 \pm 16$ & $38 \pm 15$ & $<0.01$ & $41 \pm 16$ & $38 \pm 15$ & $<0.001$ \\
\hline Randomized to receive azithromycin, N (\%) & $249(52)$ & $309(48)$ & 0.23 & $292(51 \%)$ & $266(49 \%)$ & 0.34 \\
\hline \multicolumn{7}{|l|}{ Medications for COPD, N (\%) } \\
\hline ICS only & $23(5)$ & $34(5)$ & 0.70 & $27(5 \%)$ & $30(6 \%)$ & 0.68 \\
\hline LAMAs only & $28(6)$ & $48(8)$ & 0.27 & $33(6 \%)$ & $44(8 \%)$ & 0.16 \\
\hline LABAs only & $12(3)$ & $9(1)$ & 0.18 & $15(3 \%)$ & $6(1 \%)$ & 0.08 \\
\hline ICS and LABAs & $103(21)$ & $127(20)$ & 0.56 & $120(21 \%)$ & $109(20 \%)$ & 0.60 \\
\hline ICS and LAMAs & $17(4)$ & $34(5)$ & 0.16 & $21(4 \%)$ & $30(6 \%)$ & 0.20 \\
\hline LABAs and LAMAs & $24(5)$ & $29(5)$ & 0.71 & $28(5 \%)$ & $25(5 \%)$ & 0.78 \\
\hline ICS, LABAs, and LAMAs & $233(49)$ & $295(46)$ & 0.41 & $277(49 \%)$ & $251(46 \%)$ & 0.31 \\
\hline No Inhaled COPD Meds & $39(8)$ & $62(10)$ & 0.37 & $47(8 \%)$ & $54(10 \%)$ & 0.40 \\
\hline Theophylline & $62(13)$ & $93(15)$ & 0.44 & $82(14 \%)$ & $73(13 \%)$ & 0.60 \\
\hline \multicolumn{7}{|l|}{ Anti-reflux medications at baseline, N (\%) } \\
\hline Proton pump inhibitors & $301(63)$ & $70(11)$ & $<0.01$ & $37165)$ & 0 & $<0.01$ \\
\hline Histamine-2 receptor blockers & $53(11)$ & $23(4)$ & $<0.01$ & $76(13)$ & 0 & $<0.01$ \\
\hline Antacids & $8(2)$ & $2(0.3)$ & 0.02 & $10(2)$ & 0 & $<0.01$ \\
\hline \multicolumn{7}{|l|}{ Anti-reflux medications at 12 months, $\mathbf{N}(\%)$} \\
\hline Proton pump inhibitors & $263(65)$ & $94(17)$ & $<0.01$ & $319(67)$ & $38(8)$ & $<0.01$ \\
\hline Histamine-2 receptor blockers & $48(12)$ & $27(5)$ & $<0.01$ & $63(13)$ & $12(3)$ & $<0.01$ \\
\hline Antacids & $9(2)$ & $4(1)$ & 0.05 & $9(2)$ & $4(1)$ & 0.17 \\
\hline
\end{tabular}


Table 2A.Times to First and Rates of Acute Exacerbations (GERD Defined by History)

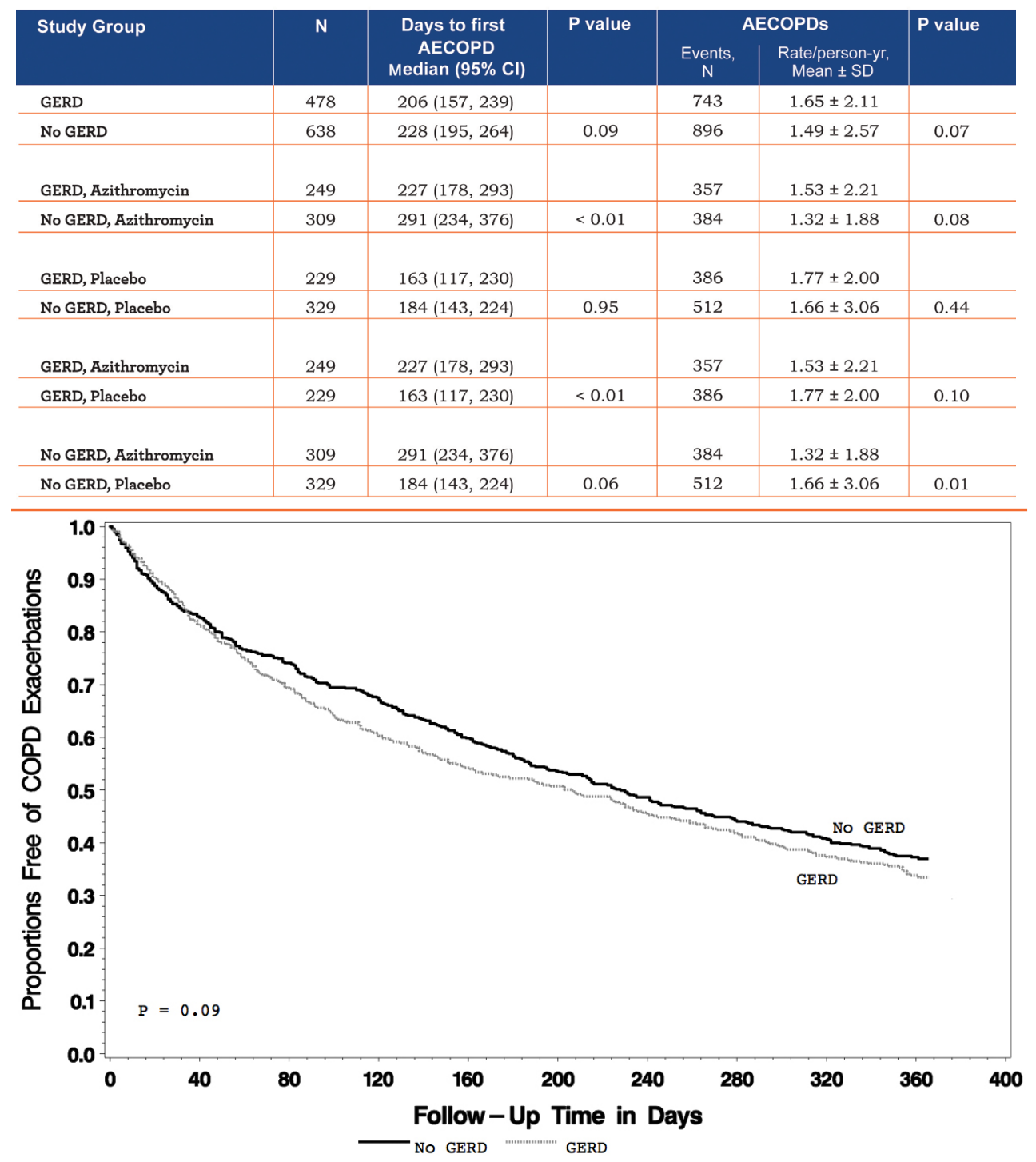

Figure 2A. Proportion Free of COPD Exacerbations by GERD, Defined by History.

\section{Table 2B.Times to First and Rates of Acute Exacerbations (GERD Defined by History or Treatment)}

\begin{tabular}{|c|c|c|c|c|c|c|}
\hline \multirow[t]{2}{*}{ Study Group } & \multirow[t]{2}{*}{$\mathbf{N}$} & \multirow{2}{*}{$\begin{array}{l}\text { Days to first } \\
\text { AECOPD } \\
\text { Median }(95 \% \mathrm{CI})\end{array}$} & \multirow[t]{2}{*}{$P$ value } & \multicolumn{2}{|c|}{ AECOPDs } & \multirow[t]{2}{*}{$P$ value } \\
\hline & & & & $\begin{array}{l}\text { Events, } \\
\mathrm{N}\end{array}$ & $\begin{array}{l}\text { Rate/person-yr, } \\
\text { Median (95\% CI) }\end{array}$ & \\
\hline GERD & 568 & $191(157,229)$ & & 895 & $1.68 \pm 2.11$ & \\
\hline No GERD & 548 & $241(211,284)$ & 0.02 & 744 & $1.43 \pm 2.63$ & 0.02 \\
\hline GERD, Azithromycin & 292 & $255(181,288)$ & & 424 & $1.55 \pm 2.23$ & \\
\hline No GERD, Azithromycin & 266 & $320(246,380)$ & $<0.01$ & 317 & $1.26 \pm 1.79$ & 0.02 \\
\hline GERD, Placebo & 276 & $146(115,216)$ & & 471 & $1.82 \pm 1.98$ & \\
\hline No GERD, Placebo & 282 & $195(151,235)$ & 0.31 & 427 & $1.60 \pm 3.21$ & 0.29 \\
\hline GERD, Azithromycin & 292 & $225(181,288)$ & & 424 & $1.55 \pm 2.23$ & \\
\hline GERD, Placebo & 276 & $146(115,216)$ & $<0.01$ & 471 & $1.82 \pm 1.98$ & 0.07 \\
\hline No GERD, Azithromycin & 266 & $320(246,380)$ & & 317 & $1.26 \pm 1.79$ & \\
\hline No GERD, Placebo & 282 & $195(151,235)$ & 0.01 & 427 & $1.60 \pm 3.21$ & 0.01 \\
\hline
\end{tabular}

statistically significantly-greater frequency of hospitalization, regardless of whether they received azithromycin or not (Table 3B). Individuals without GERD by both definitions who received azithromycin had reduced hospitalization rates compared to those given the placebo (Table 3A and Table 3B).

\section{Discussion}

We report that COPD participants with GERD had a shorter time to the first AECOPD, more frequent AECOPDs and more AECOPDrelated hospitalizations than participants without GERD, and that taking azithromycin daily for 1 year reduced AECOPDs in participants with or without GERD but was more effective in participants without GERD.

The $43 \%$ prevalence of GERD that we observed when defining GERD by history was higher than the $19 \%-27 \%$ reported by most others who defined GERD on the basis of questionnaires. ${ }^{2,5,6}$ Rogha and colleagues ${ }^{10}$ found a $66 \%$ prevalence of GERD defined by questionnaires but $85 \%$ of their participants were active smokers and smoking is known to reduce lower esophageal sphincter tone and increase GERD. ${ }^{15,16}$ Only $20 \%-24 \%$ of our participants were active smokers. The fact that our study population was limited to individuals who had an increased likelihood of experiencing an AECOPD within the year of followup may account for the higher GERD prevalence that we observed. Our finding that participants with GERD had higher body mass indexes is consistent with Jacobson and colleagues, ${ }^{17}$ observation that even moderate weight gain is associated with an increased GERD 


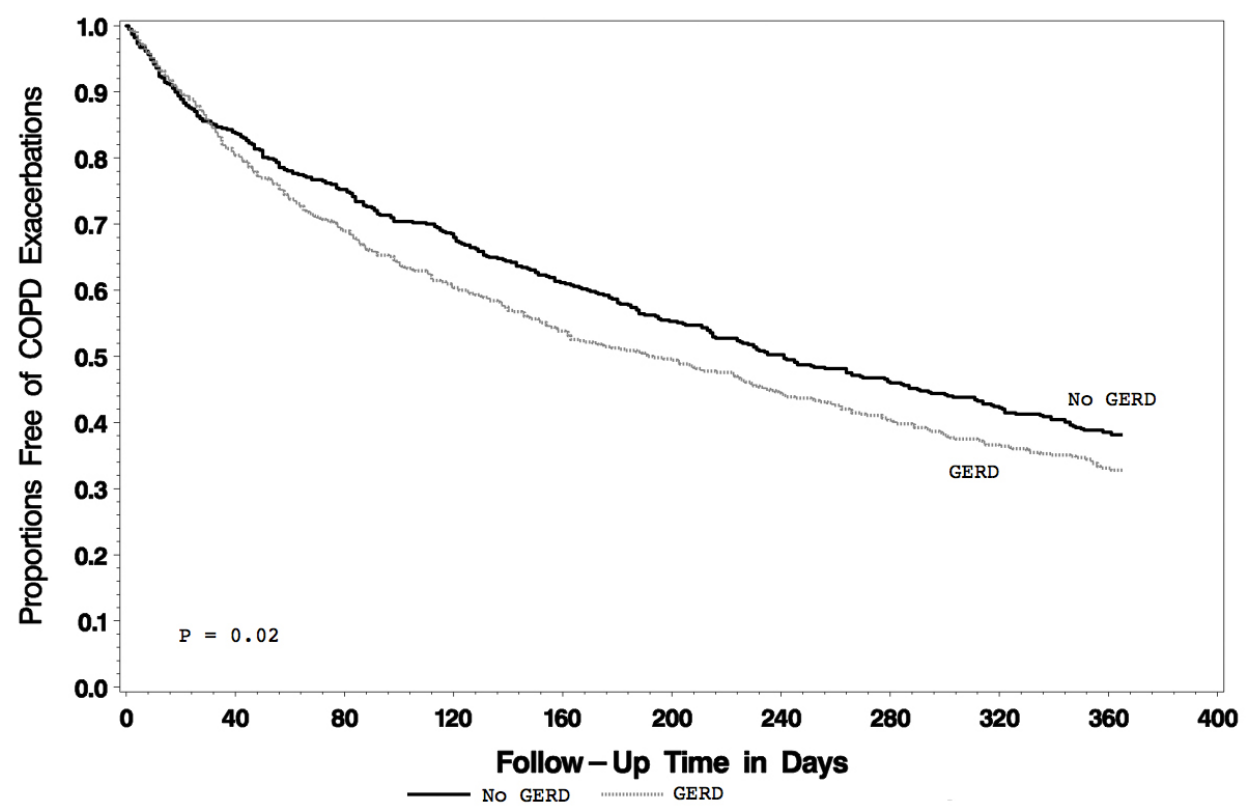

Figure 2B. Proportion Free of COPD Exacerbations by GERD, Defined by History or Treatment.

\section{Table 3A. Severity of AECOPDs (GERD Defined by History)}

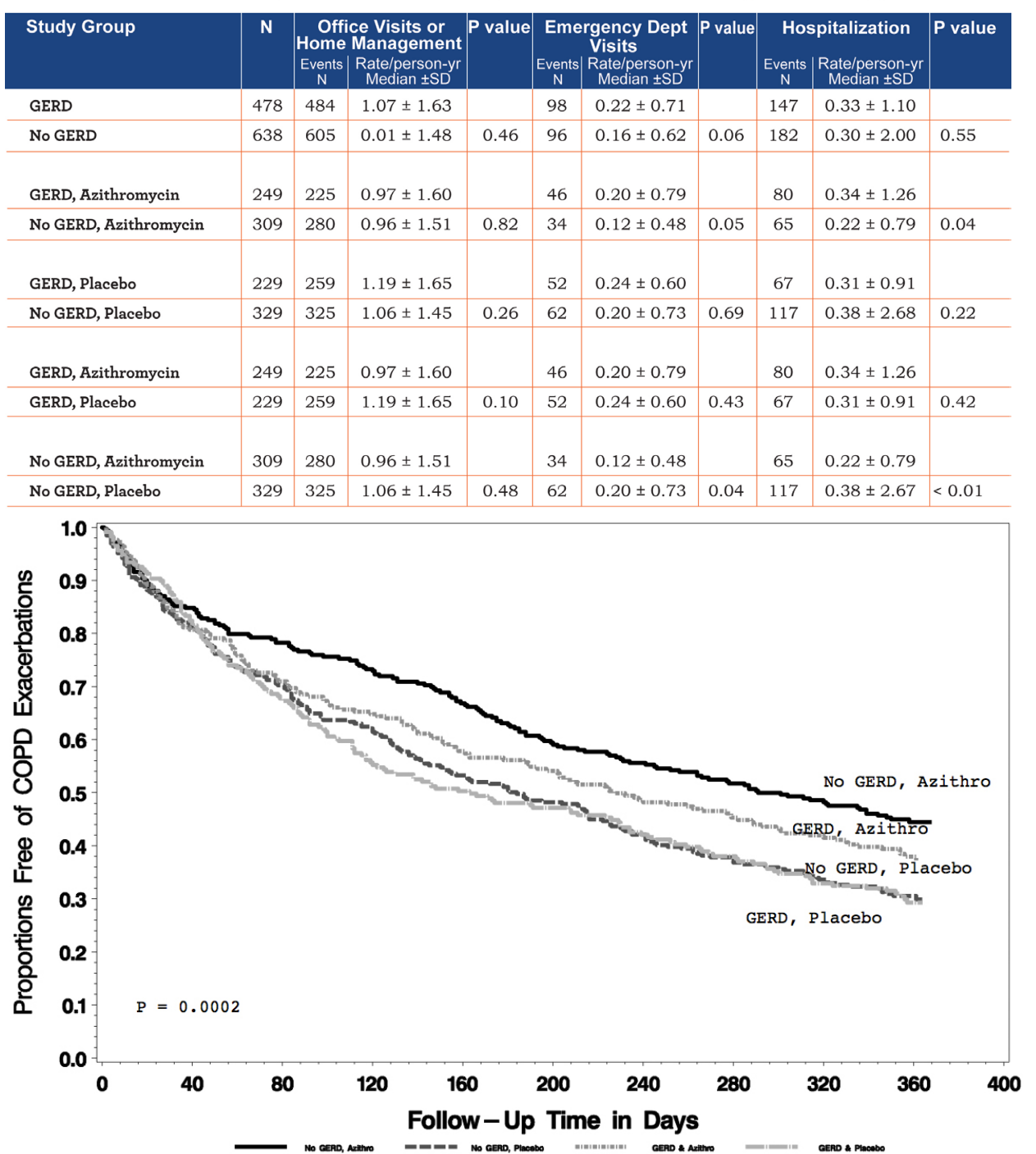

Figure 3A. Proportion Free of COPD Exacerbations by GERD (Defined by History) and Azithromycin Versus Placebo. prevalence.

Our finding that the presence of GERD was associated with a decreased time to first AECOPD and a higher rate of AECOPDs is consistent with several previous prospective and retrospective studies. $3,5,6,10$ The observation that taking azithromycin reduced AECOPDs in patients with or without GERD suggests that the mechanism of benefit is more than the medication's effect on gastric motility or reflux.

Our study had a number of limitations. First, the definition that we used for GERD, although also used in a prospective study, ${ }^{6}$ is not ideal. In the absence of 24hour esophageal $\mathrm{pH}$ monitoring we may have misclassified patients with or without GERD. However, an increased frequency of acid in the esophagus may not be an accurate reflection of GERD in individuals with COPD as it could be the result of the positive intra-abdominal pressure that is generated as a result of cough. We also observed that $11 \%$ and $4 \%$ of participants at baseline in the No GERD group were prescribed proton pump inhibitors (PPI) or histamine-2 receptor blockers, respectively. These individuals may not have been aware that they were prescribed these medications for a clinical diagnosis of GERD, the indication of therapy might not have been GERD or the PPI might have been prescribed inappropriately. ${ }^{18}$ We included a different definition of GERD, incorporating history or therapy, to provide an alternative analysis. Second, we do not have information on whether our participants had hiatal hernias; accordingly, we cannot determine if this had a differential effect on GERD and/or on the effect of azithromycin on AECOPDs. 
Third, although our findings were generally consistent regardless of how we defined GERD, the strength of the differences we observed between the groups defined by GERD symptoms or treatment varied. Fourth, a review of GERD treatment at 12 months showed that a small number of patients who were classified as having no GERD at baseline by both definitions may have received GERD treatment sometime within the one year study period. Fifth, while we found no differences in office visits or home management or in emergency department visits in participants who were taking azithromycin vs. placebo as a function of GERD, these were secondary endpoints in the original azithromycin study and, accordingly, the study was not adequately powered to allow us to conclude that no differences in these endpoints occurred. Sixth, whether a different azithromycin dosing frequency, once daily vs. twice daily, would have any effect on motility and reduction in GERD and COPD exacerbations cannot be determined with this study.

Our study also had a number of strengths. First, we provided a robust analysis of exacerbations using 2 different endpoints: time to first exacerbation and rates of
Table 3B. Severity of AECOPDs (GERD Defined by History or Treatment)

\begin{tabular}{|c|c|c|c|c|c|c|c|c|c|c|}
\hline Study Group & $\mathbf{N}$ & $\begin{array}{c}\text { Off } \\
\text { Home } \\
\text { Events } \\
N\end{array}$ & $\begin{array}{l}\text { ce Visits or } \\
\text { Management } \\
\text { Rate/person-yr } \\
\text { Median } \pm S D\end{array}$ & P value & \begin{tabular}{|c|} 
Eme \\
Events \\
$\mathrm{N}$
\end{tabular} & $\begin{array}{l}\text { rgency Dept } \\
\text { Visits } \\
\text { Rate/person-yr } \\
\text { Median } \pm S D\end{array}$ & P value & $\begin{array}{c}\text { Ho: } \\
\text { Events } \\
\mathrm{N}\end{array}$ & $\begin{array}{l}\text { spitalization } \\
\begin{array}{c}\text { Rate/person-yr } \\
\text { Median } \pm S D\end{array}\end{array}$ & $P$ value \\
\hline GERD & 568 & 580 & $1.09 \pm 1.67$ & & 107 & $0.20 \pm 0.67$ & & 191 & $0.36 \pm 1.07$ & \\
\hline No GERD & 548 & 509 & $0.98 \pm 1.40$ & 0.36 & 87 & $0.17 \pm 0.66$ & 0.24 & 138 & $0.27 \pm 2.13$ & 0.03 \\
\hline GERD, Azithromycin & 292 & 269 & $0.99 \pm 1.63$ & & 49 & $0.18 \pm 0.75$ & & 99 & $0.36 \pm 1.20$ & \\
\hline No GERD, Azithromycin & 266 & 236 & $0.94 \pm 1.38$ & 0.59 & 31 & $0.12 \pm 0.50$ & 0.16 & 46 & $0.18 \pm 0.78$ & $<0.01$ \\
\hline GERD, Placebo & 276 & 311 & $1.20 \pm 1.64$ & & 58 & $0.22 \pm 0.58$ & & 92 & $0.36 \pm 0.91$ & \\
\hline No GERD, Placebo & 282 & 273 & $1.02 \pm 1.43$ & 0.25 & 56 & $0.21 \pm 0.77$ & 0.99 & 92 & $0.34 \pm 2.87$ & 0.84 \\
\hline GERD, Azithromycin & 292 & 369 & $0.99 \pm 1.69$ & & 49 & $0.18 \pm 0.75$ & & 99 & $0.36 \pm 1.20$ & \\
\hline GERD, Placebo & 276 & 311 & $1.20 \pm 1.64$ & 0.09 & 58 & $0.22 \pm 0.58$ & 0.07 & 92 & $0.36 \pm 0.91$ & 0.64 \\
\hline No GERD, Azithromycin & 266 & 236 & $0.94 \pm 1.38$ & & 31 & $0.12 \pm 0.50$ & & 46 & $0.18 \pm 0.78$ & \\
\hline No GERD, Placebo & 282 & 273 & $1.02 \pm 1.43$ & 0.47 & 56 & $0.21 \pm 0.77$ & 0.05 & 92 & $0.34 \pm 2.87$ & $<0.01$ \\
\hline
\end{tabular}

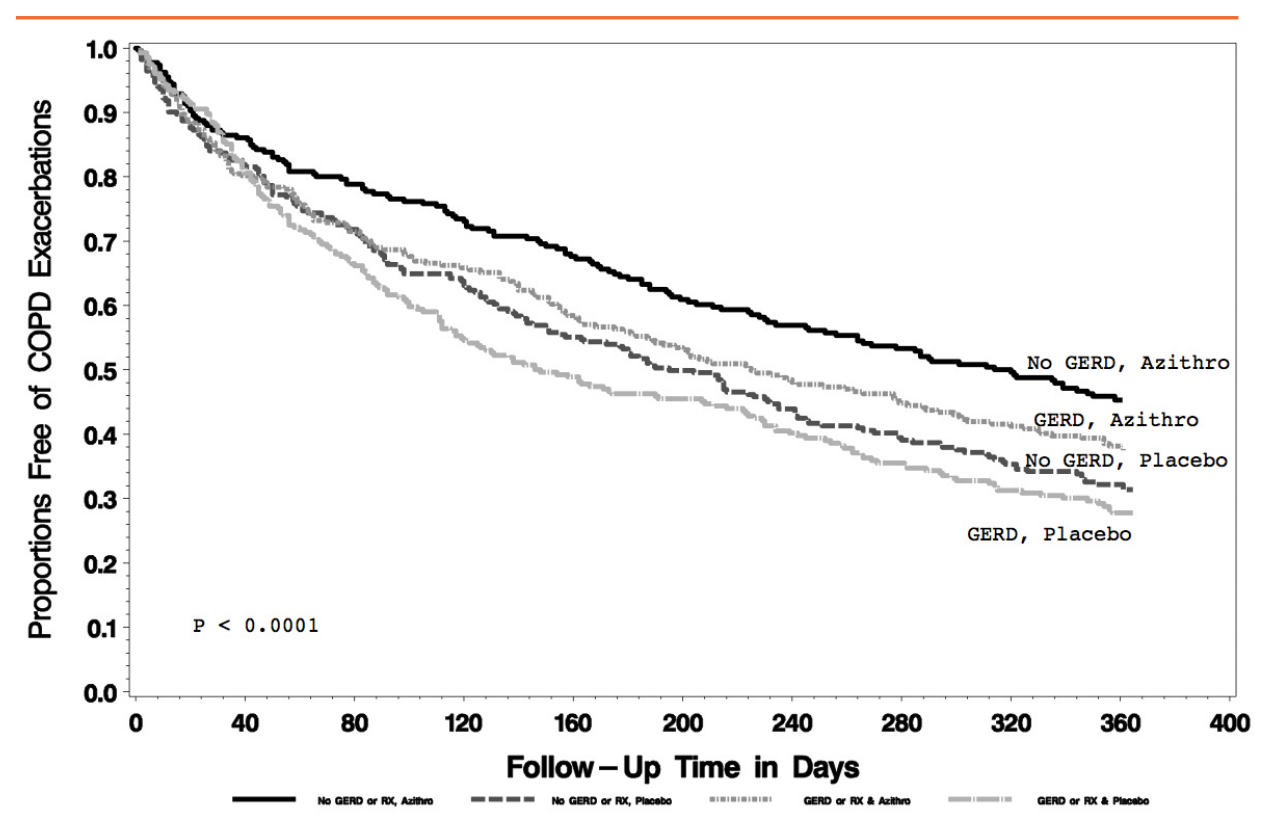

Figure 3B. Proportion Free of COPD Exacerbations by GERD (Defined by History or Treatment) and Azithromycin Versus Placebo. exacerbation. Second, we also assessed the frequency of hospitalization as a surrogate endpoint for the severity of AECOPD. Third, our data come from a large, prospective study of carefully characterized COPD individuals who were followed for the development of an AECOPD for a one-year period.

In summary, we confirmed that COPD participants with GERD have more frequent AECOPDs and are more commonly hospitalized for AECOPDs than participants without GERD. We also found that azithromycin decreased AECOPDs in COPD individuals with or without GERD, but that the effect was more pronounced in those without GERD. The prokinetic and anti-reflux effects of azithromycin are not likely explanations for its ability to decrease AECOPDs in COPD. We add to the growing body of evidence of the relationship between GERD and more frequent and severe COPD exacerbations.

\section{Conclusion}

In conclusion, COPD participants at risk for COPD exacerbations and with GERD had a shorter time to the first AECOPD, more frequent AECOPDs and more AECOPD-related hospitalizations than participants 
without GERD. In addition, taking azithromycin daily for one year reduced AECOPDs in participants with or without GERD but was more effective in participants without GERD.

\section{Acknowledgements}

None

Declaration of Interest

The authors have no real or apparent conflicts of interest including financial and consulting relationships. 


\section{References}

1. Casanova C, Baudet JS, del Valle Velasco M, et al. Increased gastro-oesophageal reflux disease in patients with severe COPD. Eur Respir J. 2004; 23(6):841-845.

doi: http://dx.doi.org/10.1183/09031936.04.00107004

2. Mokhlesi B, Morris AL, Huang CF, Curcio AJ, Barrett TA, Kamp DW. Increased prevalence of gastroesophageal reflux symptoms in patients with COPD. Chest. 2001;119(4):1043-1048. doi: http://dx.doi.org/10.1378/chest.119.4.1043

3. Rascon-Aguilar IE, Pamer M, Wludyka P, et al. Role of gastroesophageal reflux symptoms in exacerbations of COPD. Chest. 2006;130(4):1096-1101. doi: http://dx.doi.org/10.1378/chest.130.4.1096

4. Kempainen RR, Savik K, Whelan TP, Dunitz JM, Herrington CS, Billings JL. High prevalence of proximal and distal gastroesophageal reflux disease in advanced COPD. Chest. 2007;131(6):1666-1671.

doi: http://dx.doi.org/10.1378/chest.06-2264

5. Terada K, Muro S, Sato S, et al. Impact of gastro-oesophageal reflux disease symptoms on COPD exacerbation. Thorax. 2008;63(11):951-955.

doi: http://dx.doi.org/10.1136/thx.2007.092858

6. Hurst JR, Vestbo J, Anzueto A, Evaluation of COPD longitudinally to Identify Predictive Surrogate Endpoints (ECLIPSE) Investigators. Susceptibility to exacerbation in chronic obstructive pulmonary disease. N Engl J Med. 2010; 363(12):1128-1138.

doi: http://dx.doi.org/10.1056/NEJMoa0909883

7. Dent J, El-Serag HB, Wallander MA, Johansson S. Epidemiology of gastro-oesophageal reflux disease: A systematic review. Gut. 2005; 54(5):710-717.

doi: http://dx.doi.org/10.1136/gut.2004.051821

8. Boyle JT, Tuchman DN, Altschuler SM, Nixon TE, Pack AI, Cohen S. Mechanisms for the association of gastroesophageal reflux and bronchospasm. Am Rev Respir Dis. 1985.131(5):S1620.

9. Schan CA, Harding SM, Haile JM, Bradley LA, Richter JE. Gastroesophageal reflux-induced bronchoconstriction. An intraesophageal acid infusion study using state-of-the-art technology. Chest. 1994;106(3):731-737.

doi: http://dx.doi.org/10.1378/chest.106.3.731

10. Rogha M, Behravesh B, Pourmoghaddas Z. Association of gastroesophageal reflux disease symptoms with exacerbations of chronic obstructive pulmonary disease. J Gastrointestin Liver Dis. 2010;19(3):253-256.

11. Sasaki T, Nakayama K, Yasuda H, et al. A randomized, singleblind study of lansoprazole for the prevention of exacerbations of chronic obstructive pulmonary disease in older patients. $J$ Am Geriatr Soc. 2009;57(8):1453-1457. doi:

http://dx.doi.org/10.1111/j.1532-5415.2009.02349.x
12. Albert RK, Connett J, Bailey WC, COPD Clinical Research Network, et al. Azithromycin for prevention of exacerbations of COPD. N Engl J Med. 2011;365(8):689-698. doi: http://dx.doi.org/10.1056/NEJMoa1104623

13. Rohof WO, Bennink RJ, de Ruigh AA, Hirsch DP, Zwinderman AH, Boeckxstaens GE. Effect of azithromycin on acid reflux, hiatus hernia and proximal acid pocket in the postprandial period. Gut. 2012;61(12):1670-1677. doi: http://dx.doi.org/10.1136/gutjnl-2011-300926

14. Mertens V, Blondeau K, Pauwels A, et al. Azithromycin reduces gastroesophageal reflux and aspiration in lung transplant recipients. Dig Dis Sci. 2009;54(5):972-979.

doi: http://dx.doi.org/10.1007/s10620-009-0725-4

15. Kahrilas PJ. Cigarette smoking and gastroesophageal reflux disease. Dig Dis. 1992;10(2):61-71. doi: http://dx.doi.org/10.1159/000171345

16. Pandolfino JE, Kahrilas PJ. Smoking and gastro-oesophageal reflux disease. Eur J Gastroenterol Hepatol. 2000;12(8):837842. doi:

http://dx.doi.org/10.1097/00042737-200012080-00002

17. Jacobson BC, Somers SC, Fuchs CS, Kelly CP, Camargo CA,Jr. Body-mass index and symptoms of gastroesophageal reflux in women. N Engl J Med. 2006 ;354(22):2340-2348. doi: http://dx.doi.org/10.1056/NEJMoa054391

18. Reid M, Keniston A, Heller JC, Miller M, Medvedev S, Albert RK. Inappropriate prescribing of proton pump inhibitors in hospitalized patients. J Hosp Med. 2012;7(5):421-425. doi: http://dx.doi.org/10.1002/jhm.1901 